\title{
Productive economies, inclusive societies
}

Last update: 13 March 2017

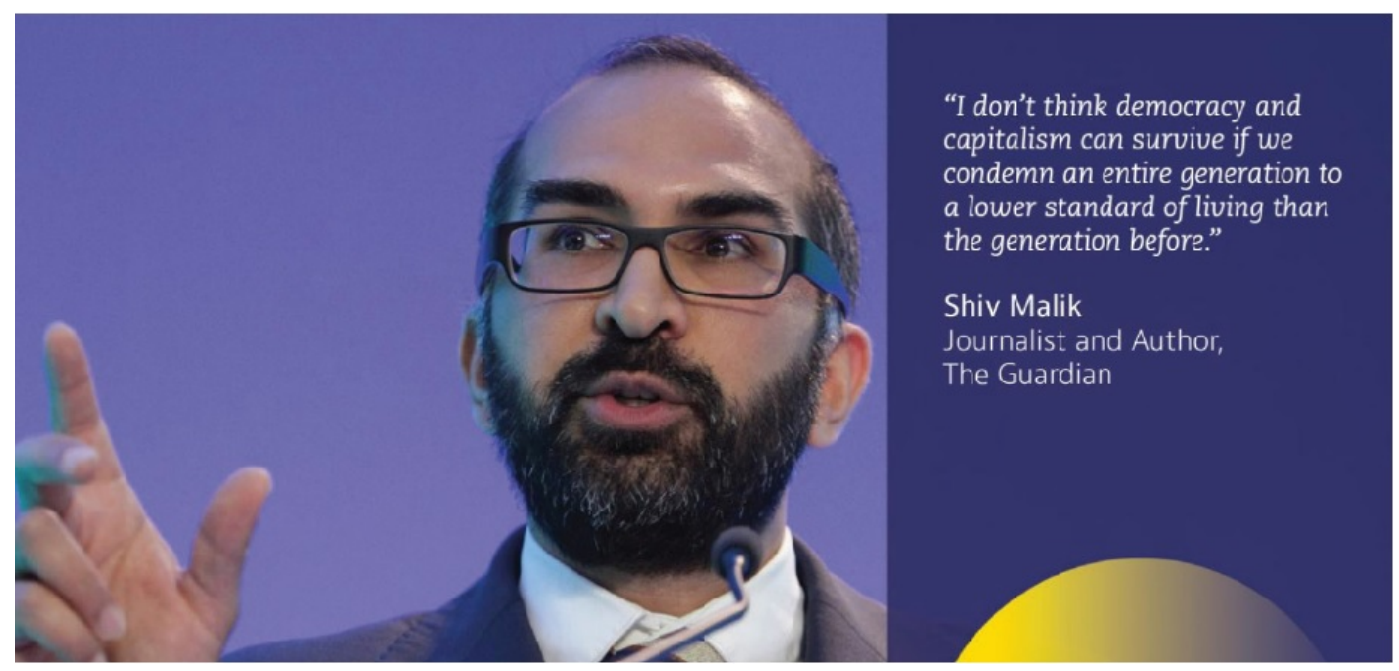

Inequalities, productivity and the digital economy are major concerns among citizens and policy makers, and these issues guided the key cross-cutting discussions at the OECD Forum on 31 May-1 June.

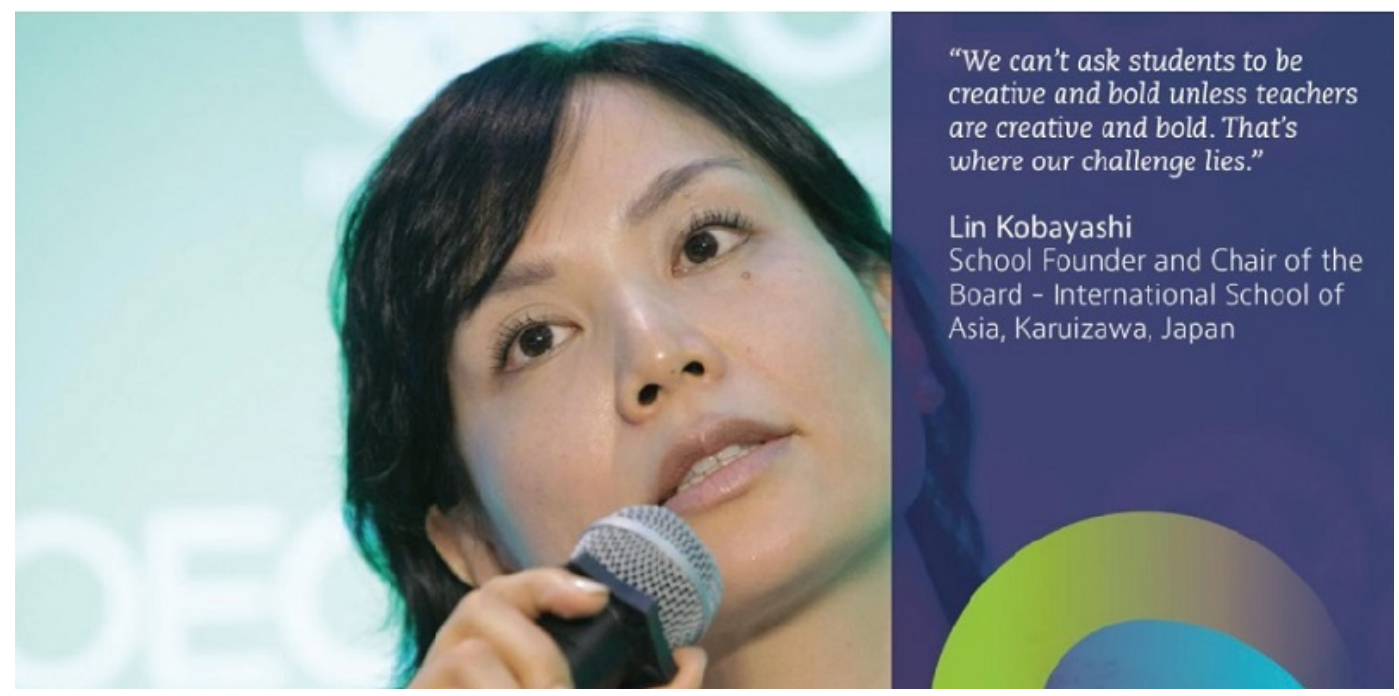

The OECD Forum is a valuable opportunity for concerned citizens to debate the issues and garner new ideas ahead of the annual OECD Ministerial Council Meeting. Indeed, since its creation in 2000, this relationship with a major ministerial gathering has established the OECD Forum as a "must-go" multi- 
stakeholder event on the global calendar, and the 17th edition lived up to the billing.

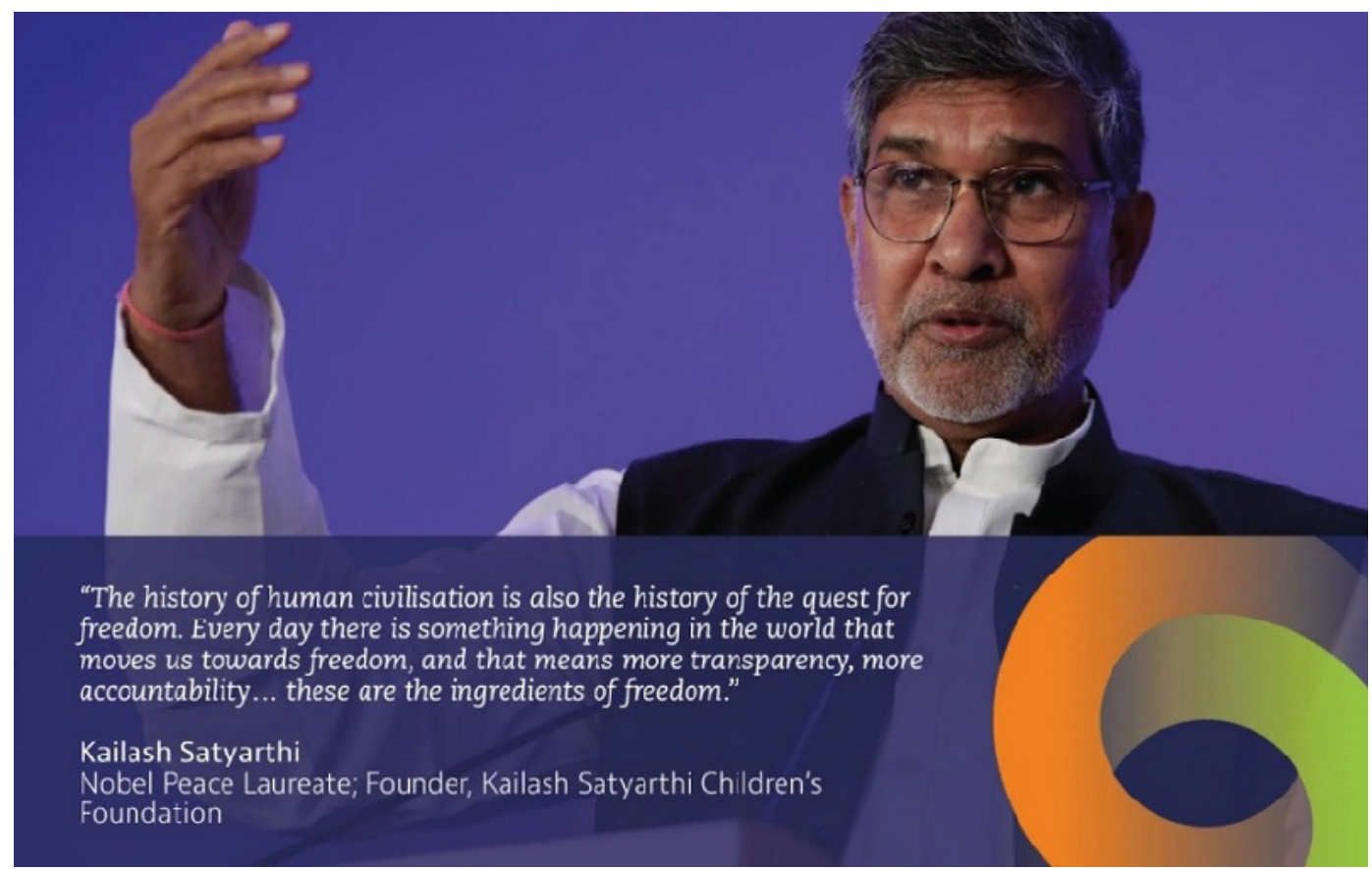

Some 2,700 participants from over 60 countries gathered to listen to experts, meet authors and network among idea factories, discovery labs, lunch debates and discussion cafés. People such as Nobel Peace Laureate Kailash Satyarthi, International School of Asia founder Lin Kobayashi, writer and journalist Shiv Malik, and CEO of Save the Children International, Helle Thorning-Schmidt, were among the 275 speakers and panellists from politics, business, labour, civil society, academia and the media to lead this year's discussions. Many thousands of people followed the debates online and via social media channels, and tried out and shared the latest release of the OECD Better Life Index.

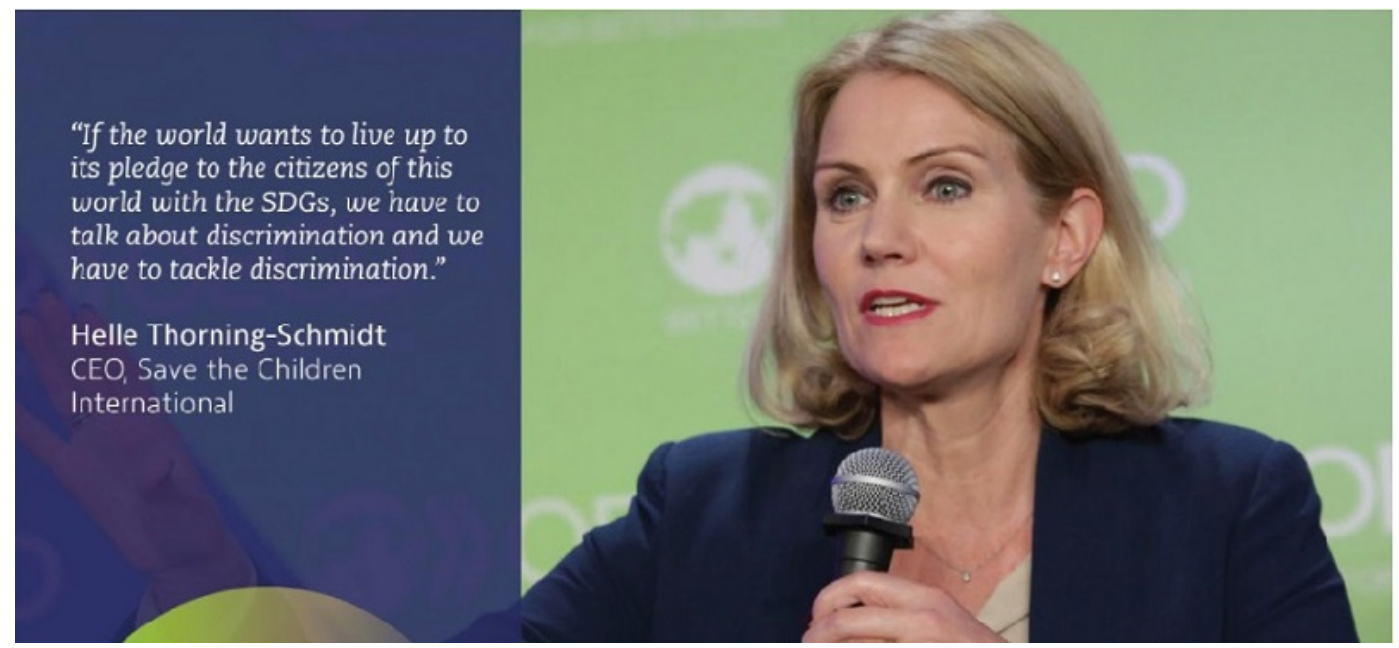


For highlights and a list of main speakers, see www.oecd.org/forum.

For reflections and outcomes of the 2016 OECD Forum, see http://oe.cd/1AS

Visit www.oecdbetterlifeindex.org

3 www.oecdobserver.org | Productive economies, inclusive societies 